logos_i_ethos_2020_1_(53), s. 179-193

DOI: http://dx.doi.org/10.15633/lie.3695

\title{
Helen Watt
}

https://orcid.org/0000-0002-4605-339X

Anscombe Bioethics Centre

\section{Improving Unjust Laws Without Inviting Unjust Plans: The Case of Abortion for Fetal Anomaly}

\section{Introduction}

All human individuals, including those still living in and nurtured by their mothers, have rights concerning their own lives, however long or short those lives may be. That view is, of course, contested, but I will here assume its truth in order to focus on other things. I will argue from - not for - a stance of opposition to discriminatory targeting of any human being, whether on the basis of location, age, dependency, state of health or level of ability. We are all equal, at least as regards our moral right to immunity from deliberate lethal attacks we have done nothing to deserve.

Abortion for fetal anomaly in fact gives every sign of being a form of abortion especially likely to cause the woman anguish and complicated
Dr Helen Watt - is Senior Research Fellow of the Anscombe Bioethics Centre and a Research Fellow of Blackfriars Hall, Oxford. Her publications include Life and Death in Healthcare Ethics (London 2000) and The Ethics of Pregnancy, Abortion and Childbirth (New York 2016) together with several edited volumes including Incapacity and $\mathrm{Ca}$ re (London 2009) and Fertility and Gender (Oxford 2011). Her research interests include reproductive ethics, gender, action theory, and issues of cooperation and conscientious objection. 
grief: ${ }^{1}$ complicated by the fact her baby's death was chosen by her, with whatever sadness and reluctance. The woman's violent loss of the child with whom she has lived for so many weeks can have a truly shattering impact on her, as research ${ }^{2}$ and personal stories ${ }^{3}$ show. Nor is it enough to appeal to the woman's guardianship of her pregnancy and claim that this extends to a right to end it, even if this is not in the woman's actual interests or those of her baby. It is no part of guardianship to choose to end a life in one's care, even for altruistic motives, or lethally to evict ${ }^{4}$ that life from archetypally maternal, very basic shelter and support.

In this article, I want however to explore, not so much the issue of abortion per se, as that of lawmaking in response to existing injustice, with abortion for disability as a case in point. How should we address laws that perhaps cannot be entirely abrogated in some existing political climate, where such laws enable lethal discrimination against members of a certain group? If we fail to protect all human beings in restrictive legislation, will we ourselves be guilty of unjust discrimination? Or does that depend on, to begin with, what exactly we are intending (and intend that others intend)? Can the legal situation in Britain, for example, where abortion is permitted up to birth for disability be addressed without at the same time addressing the injustice of abortion on other grounds, and at earlier stages? What, in short, are the moral constraints

1 A. Kersting, K. Kroker, J. Steinhard et al., Complicated Grief after Traumatic Loss, "European Archives of Psychiatry and Clinical Neuroscience" 257 (2007), p. 437-443.

2 A recent study comparing abortion to continuing the pregnancy in the case of a life-limiting fetal condition found that while both groups of women were deeply affected by the experience, those who had abortions showed significantly more despair, avoidance and depression than those who continued the pregnancy. H. Cope, M. E. Garrett, S. Gregory and A. Ashley-Koch, Pregnancy continuation and organizational religious activity following prenatal diagnosis of a lethal fetal defect are associated with improved psychological outcome, "Prenatal Diagnosis" 35 (2015), p. 761-768.

3 For a pro-choice collection of such stories, see Our Heartbreaking Choices: Forty-Six Women Share Their Stories of Interrupting a Much-Wanted Pregnancy, ed. C. Brooks, Bloomington 2008. For a discussion of some themes emerging from this collection, see H. Watt, Abortion for Life-Limiting Foetal Anomaly: Beneficial When and for Whom, "Clinical Ethics" 12 (2017), p. 1-10.

4 On lethal eviction pre-viability without the aim to end life (an aim which is, however, normally present in abortion for disability) see H. Watt, A. McCarthy, Targeting the fetal body and/or mother-child connection: vital conflicts and abortion, „Linacre Quarterly” 87 (2020), p. 147-160. 
on sincere and well-motivated attempts to extend the protection of the law to more threatened individuals, although still not to all? ${ }^{5}$

\section{2. 'Selective bans' versus 'regulation'}

In looking at this question, I want to distinguish between two ways of addressing laws enabling serious injustice. ${ }^{6}$ I will argue that the first approach is morally allowable in principle, even if in practice it can create confusion and/or fail to protect those who could - and therefore prima facie should - be protected by more inclusive reforms. The second approach, while also sometimes tempting to those who want to save lives and limit harm generally is nonetheless unfortunately ruled out in principle, or so I will maintain. While sensitivity to intended means involving the choices of others can severely restrict what appear as possible options, I would hope that many readers would take the non-consequentialist view on which, proverbially, 'the end does not justify the means' - or not, at any rate, some means. It is not just good ultimate intentions, but good intentions (purposes) all the way up our 'chain' of intentions that is necessary, if not always sufficient, for full respect for others and ourselves.

Let me begin, then, with the first approach to harm limitation: what I will call 'selective banning' i.e. focusing on one particular area in which it may be possible to achieve legal protection for some threatened human beings, or at least, to make some helpful public statement. For example, abortion on the overt ground of disability might be proscribed,

5 For discussion of these issues, see J. Finnis, Helping enact unjust laws without complicity in injustice, "American Journal of Jurisprudence" 49 (2004), p. 11-42, reprinted with additional notes as Just votes for unjust laws, in: J. Finnis, Philosophy of Law. Collected Essays: Volume IV, New York 2011; C. Harte, Changing Unjust Laws Justly, Washington 2005; and also the debate between Finnis and Harte in Cooperation, Complicity and Conscience, ed. H. Watt, London 2005. For more on my own position (falling somewhere between the positions of these two authors) see H. Watt, Addressing Unjust Laws Without Complicity: Selective Bans versus Regulation, in: Contemporary Controversies in Catholic Bioethics, ed. J. Eberl, Dordrecht 2017, p. 567-582.

6 These approaches are not exclusive, and 'regulation' can of course be permissible where the action regulated is permissible or potentially permissible. 
even if abortion, at least before some general time limit, could still be performed on other grounds. Alternatively, prenatal tests, ${ }^{7}$ invasive or otherwise, might be proscribed if overtly geared to a possible abortion, or prohibited entirely if there is no urgent need to protect health of a kind to outweigh the risks of invasive testing. As regards selective bans on abortion procedures, the practice of feticide, an injection to the heart of the fetus to prevent it being born alive, might be prohibited to allow at least some babies to survive terminations which are not immediately destructive.

\section{Risk of 'selective ban' approach}

I should emphasise again that there can be serious practical ${ }^{8}$ objections to selective prohibition - for example, where it is possible to be more ambitious in the scope of those protected and/or where we risk sending out harmful social messages by the limited scope of the proposed law. Such messages could be sent out by a Bill prohibiting abortion except where the baby has anencephaly (or some other life-limiting condition): a move that could create serious confusion generally and specifically present complicity problems when collaborating with those who positively want abortion to be available to women on that ground (I will come back to this later on). As well as the risk of further undermining respect for anencephalic babies - already a targeted and highly vulnerable group - there is the likelihood of sending out a very demoralising message to those parents expecting or mourning such babies who do not in any way doubt their child's right to live. Paradoxically, a less inclusive, perhaps more clearly arbitrary Bill simply to prohibit abortion for a particular condition such as Down's Syndrome may carry a lower risk of sending out bad messages than one prohibiting abortion for everything but anencephaly. Lawmakers and lobbyists could

Prenatal tests for sex determination, for example, are currently prohibited in India.

8 Such practical objections are discussed (in addition to in-principle questions) in C. Harte, Changing Unjust Laws Justly, op. cit., Part 1. 
focus their efforts, not negatively on children with other conditions, but positively on those with Down's, while saying openly that they are themselves opposed to all abortions: nothing is conceded about the propriety of abortion in other cases which the Bill does not address. Certainly, those with Down's should not be presented as 'honorary able-bodied' people to whom the lethal acts of elimination supposedly rightly applied to those with more serious conditions should not be extended.

\section{In-principle permissibility of selective bans}

Selective bans can, in short, raise genuine moral problems, and it can be wrong at least to propose and promote - if not necessarily to vote for such prohibitions. All that said, though, selective bans as such clearly cannot be rejected out of hand. After all, any time we try to prevent any injustice, we are focusing on that specific evil and not on other evils, perhaps no less heinous, which are however left for another day. Even a proposed law prohibiting all abortions will not necessarily cover the destruction of IVF embryos, let alone other evils such as euthanasia, in a legislature that allows this. Failing a revision of the entire criminal code in such a way as to protect the rights of all, there is no escape from the need to single out particular threatened groups at particular times that we think we may have some chance of protecting. Such proposed selective legislation does not 'permit' the remaining injustices in the sense of making them permitted, ${ }^{9}$ but simply leaves them permitted whether or not those still permitted are specifically mentioned in the Bill. Of course, that also applies to legislation which would prohibit abortions in a certain geographical area, and which again, might acknowledge explicitly that abortion will remain permitted elsewhere. Here too, choosing not to try at once to ban all abortions need not involve the intention that any occur or be offered any more than a lawyer defending one political prisoner intends the execution of those he will not defend. (Also worth noting is the fact that those who oppose all abortion, whatever their view of voting for selective 
bans, will often welcome or initiate moves to enforce existing selective bans where again, such moves need not constitute complicity with those abortions that remain within the law.)

\section{Selective bans during and after the passage of laws}

'Selective banning' involves both attempts to amend existing legislation, and also attempts to amend proposed legislation during the passage of a relevant Bill. For example, in Britain some legislators (a minority) voted against extending abortion up to birth for disabled unborn children during the passage of the Human Fertilisation and Embryology Bill 1990. Voting against this at the time on the one hand, and after the Bill has been passed on the other, would seem to be somewhat similar morally: if one is allowable at least in principle (at a point where a vote against all abortion is not available to lawmakers), the other should be allowable too. Looking back to the Abortion Act 1967, there were some who wished to remove the disability clause at the time it was being debated, while more recently, the Shinkwin Bill proposed by a disabled peer in the House of Lords has been aimed at removing the same clause. Again, if it was right to try to remove the clause originally, to limit the harm of the impending law in terms of targeting disabled babies in particular, then it should be right, at least in principle, to remove the clause now.

\section{6. 'Regulatory' approaches to wrongful actions}

I will return later to the opportunities and challenges that 'selective ban' approaches can present. For the moment, I will turn to a different approach to legislation: if selective bans are at least sometimes morally appropriate, what kind of legislative change am I claiming is always morally excluded? I will call this morally excluded change 'regulation' - by which I mean not just setting up a 'regulatory body', but any change intended to instruct people how to prepare for or perform an unjust act, or otherwise aimed at motivating them to perform or prepare in a certain way. 
It can be very tempting to support legislation of this kind, in the hope of saving at least some lives and otherwise minimising harm; for example, harm to the woman who may find herself very quickly on the abortion 'conveyor belt', lacking all but the most minimal information on her abortion and on support available to have her child. However, as we think about requirements on abortion doctors, we need to remember that preparing to do wrong, as well as carrying out the final act perhaps in some amended version are themselves wrongful choices, whether or not the person knows this. On a classic understanding of the principles of complicity, which though demanding are nothing if not logical, we may never intend a wrongful choice by another, any more than by ourselves. It would seem to follow that counselling or mandating the "lesser evil' is something that has to be avoided: ${ }^{10}$ muggers should not be told to steal in less violent ways, or child abusers to abuse children 'more safely'. There is a crucial difference between, on the one hand, warning people to avoid some particular wrongful act above all, and on the other hand, giving them instructions how to perform or prepare for a perhaps slightly mitigated, but still clearly wrongful act. (Of course, this would not necessarily affect advice or instructions that apply once the deed is done: just as dangerous drivers are expected to stop and look after their victims, abortion doctors could be expected to offer aftercare, and inform women of post-abortion counselling, hopefully counselling independent of those who do or arrange abortions. Even if in practice abortion doctors might make advance preparations to provide such information and aftercare, such preparations need not always themselves be intended by the legislator, or be a necessary causal means to his/her end.)

\section{Avoiding 'regulation': some ambiguities}

A law requiring doctors to give details of the baby's disability on the abortion form, in the hope of preventing abortion for some less serious conditions, would appear to raise the objection that the doctor 
is being told effectively how to prepare for a possible abortion. Unless we are aiming not that any doctor use the form, but rather simply that it be circulated as a vehicle to advertise new abortion restrictions, it does seem that we are intending some doctors complete - or at least begin - specified abortion preparations. Similarly, to ask an abortion doctor to make a case to a committee for ending the life of a particular disabled baby - for example, to prove that the baby's condition is in fact terminal - would seem to be asking the doctor to prepare for a possible abortion, albeit in ways that allow the abortion to be blocked if the committee is not convinced. Even in the standard case of a doctor filling out a form, there is a general problem with requiring paperwork asserting that the demands of the law have been met as a condition of the abortion going ahead. By requiring doctors to complete such forms, are we not mandating necessarily wrongful preparation for a wrongful life-terminating act?

It is worth noting that superficially similar measures may constitute either a selective ban of, or regulation of an unjust action, depending on the details. One example would be requiring a mandatory time period in between receiving adverse prenatal test results and having an abortion. Such a delay is certainly very desirable in itself: it would give the woman who has just received highly distressing news a breathing space to think about her pregnancy, get more information and access positive help. In principle, such a mandatory delay could be framed and intended as a mere selective ban - i.e. abortions simply would not be permitted before a given number of days following the diagnosis. However, adding detailed instructions could turn the ban into 'regulation' i.e. abortion doctors might be instructed to complete paperwork giving the date on which test results were communicated as a condition of the abortion going ahead. Such advance instructions are to be avoided, as we would then be back in the area of intending preparation to end a life - or at very least, intending the doctor do something he or she will in practice do very much as part of such preparation. As regards medical records of test results being given, and which show the stage of the pregnancy, it may be only via such records that we learn that the law concerning 
waiting periods and/or upper limits for abortion has been breached. However, standard medical records can perhaps be regarded as 'existing background' rather than as something whose completion in a specified form we ourselves would be mandating.

Should abortion doctors be required to give women certain information before doing the abortion? That sounds again very welcome but again, there is a concern that this involves our intending that abortion doctors undertake something they, and perhaps we too, see as preparation for abortion - particularly when the doctor records on the abortion form that the information has been given. There is also a practical objection: gynaecologists, even those not personally implicated in abortion, will have relatively little experience of caring for disabled children and are often not well placed to give parents balanced and accurate information on what such care involves. It seems better to mandate such information provision not before an abortion, but after some already-completed action such as prenatal diagnosis (about which more below). In contrast, if we know that a doctor's fundamental if not sole motive in providing information and recording such provision is to ensure that an abortion can go ahead legally should the woman still wish it, this motivation will be at least a causal means to our end, and perhaps one we intend ourselves once we realise what is going on. The doctor's aim to prepare is, at any rate, an illicit and central part of what will promote the success of our overall plan.

\section{Warning and punishing without complicity}

That said, we should also remember that it is possible to warn people of penalties for not doing something without telling people to do or otherwise intending they do what they would be punished for omitting. An example may help here: think of an older man who is pressuring a teenage girl for sex. We can warn him that he will be punished for rape if he does not get the girl's consent without in any way intending he get her consent for what we may still regard as an act of sexual exploitation. Something similar can be said about abortion: we can warn an abortion 
doctor of legal consequences if he does not get the consent of, say, a mentally disabled woman without telling him to get her consent or otherwise intending that he do so. Of course, the doctor may well regard our warning as an instruction how to do an abortion within the law: we can only try as best we can to minimise the risk of giving any such misleading impression. In any event, it is much more justifiable to penalize the absence of consent from the woman should this absence be discovered than to give the doctor an abortion-focused consent protocol, with the intention it be used.

\section{Mandating information after prenatal diagnosis}

In any case, these worries would not apply to information required to be given, not before an abortion as such, but simply after a prenatal diagnosis by those responsible for the woman's care at that point, whatever their connection with any possible abortion. Even if a particular test was morally unjustified - say, because it put the woman and her baby at unnecessary risk of miscarriage - having done the test and got a certain result, those responsible could have a legal as well as a moral duty to inform the woman and her partner of positive options ${ }^{11}$ and support available. Many parents have said that they were inadequately informed about the condition diagnosed in their baby, and many have also said that the attitudes of health care professionals they spoke to initially were in fact very negative and unsupportive concerning their child's condition. ${ }^{12}$ It is worth remembering that parents may be particularly vulnerable on first hearing the diagnosis and have difficulty even processing

11 This would include discussing the possibility of fostering or adoption, at least in the case of parents not well placed to care for a child with a certain condition - for example, because their own health is very poor.

12 See e.g. K. Redlinger-Grosse, B. A. Bernhardt, K. Berg, M. Muenke, B. B. Biesecker, The decision to continue: The experiences and needs of parents who receive a prenatal diagnosis of holoprosencephaly, "Am. J. Med. Genet" 112 (2002), p. 369-378; M. Riordan, Maternal serum testing: Is invasive testing a passing era?, "Bioethics Research Notes" 24 (2012), p. 7-11; K. McGovern, Continuing the pregnancy when the unborn child has a life-limiting condition, "Chisholm Health Ethics Bulletin" 17 (2012), p. 1-12. 
the information they are given, strengthening the case for mandatory delay as well as the offer of help should the pregnancy continue. It would be good to see a requirement that couples receive information on support available as regards, say, special schools, financial help from the State generally and, for babies with life-limiting conditions, perinatal hospice support. ${ }^{13}$

To avoid negative and inaccurate communications, written information ${ }^{14}$ might be required to be offered that has been prepared by a charity providing support to individuals with the condition together with their families and carers. In addition to any general information provided, there should be an explicit offer to connect the couple with an affected adult or with parents who have cared for a child with the relevant condition. Such individuals are perhaps more likely than most to take an attitude to the disability which is both positive and realistic, and to show solidarity both with the couple and with the child they are expecting. ${ }^{15}$ Again, this offer should be required as following prenatal diagnosis, not as preceding abortion, not least because expectant parents who will in any case have their babies have a right to be supported too. More importantly, it is much easier to frame requirements for what happens after some wrongful procedure - including high risk and/or eugenic testing than to frame requirements focusing on what happens before or during the wrongful procedure, at the risk of mandating or otherwise intending wrongful acts or preparations.

13 For information including a bibliography on the perinatal hospice approach following prenatal diagnosis of a life-limiting condition, see the website of Perinatal Hospice and Palliative Care at www.perinatalhospice.org.

14 Wherever possible, the information should be designed for giving post-natally, and ideally should not include any reference to abortion, least of all a mention of abortion as if this were a possible 'solution' to the 'problem' of carrying a disabled child.

15 Examples of such peer support networks include anencephaly.info, Be Not Afraid, One Day More, Every Life Counts, and Prenatal Partners for Life. There is no reason why the State should not signpost the services of such organisations more often and support them as appropriate (perhaps by assisting with phone or travel costs of volunteers). 


\section{Political collaboration without complicity}

Earlier in this article, I mentioned the complicity problems that can arise for lawmakers collaborating with colleagues who are not merely modest in their current plans for reform but positively want and intend some disability abortions to be offered to women - i.e. this is one of their aims in supporting limited reform. Of course, here as elsewhere, to call this a wrongful aim is not to make a judgement on the person who has that aim, who may be entirely in good faith, even if his or her position is morally inconsistent and even morally abhorrent. Whatever the person's good faith, objectively wrongful choices on his or her part should not be deliberately invited by more consistent legal reformers. This can happen even without any interaction, as when reformers who would welcome a complete ban on abortion but suspect they cannot achieve this might count on the exception-free Bill they introduce being amended by those who want to keep some abortions available to women - following which (wrongly-motivated) amendments, the Bill would have more chance of being passed. Even if the motive itself is not intended by the more consistent reformers who tacitly will that the amendments be made by their colleagues, the fact that this deeply unjust motive will be the driving force behind their colleagues' actions makes this a key causal means, at least, to the end they themselves hope to achieve. 'Using' their colleagues in this way i.e. opportunistically drawing them into an act in practice very much motivated by at least one deeply unjust aim seems difficult to defend. ${ }^{16}$ Far better if the more consistent reformers present a suitably modest proposal in the first place and simply invite their less consistent colleagues to focus on that proposal alone. After all, there is no need for any lawmaker to intend the continued offer to women of those kinds of abortion whose legal availability is in any case untouched by the Bill concerned.

\footnotetext{
16 We would not, for example, even tacitly invite a family member to buy a gun we know he will use in the first instance in an honour killing, though also to defend other family members.
} 


\section{Conclusion}

In making such arguments, I am aware that this interrogation of means may seem over-scrupulous to those confronting a culture where 'conditional parenthood' is everywhere promoted and where a large majority of disabled babies never see the light of day. In my defence, I can only say that those wishing to uphold human rights, including the right to life, should be in fact the first to oppose any suggestion that a good end justifies any means. If it were a re-zoning Bill in question, I hope that no reader would deliberately appeal to a corrupt politician to vote with the aim of crushing his enemies or endearing himself to organized crime. Good ends must be sought by good means only, and never by bad means. While we can certainly tolerate bad 'parallel' chains of reasoning where people have both good and bad motivations in what they do, we should not deliberately invite, or recklessly and proactively enable, any aim which is unjust or corrupt.

As regards the legislation itself, I have been arguing that what I call 'regulation', where wrongful acts and preparations are intended by lawmakers, is wrong in principle: again, we must choose other, morally good means of making a bad situation better. These alternative means include selective banning of some bad actions and the mandating of other actions which are good or potentially good in the context in which they are mandated.

As regards abortion for disability in particular, the State certainly has a very strong interest in preventing this - in some ways even stronger than its interest in preventing abortion more generally. Aside from the loss to the child of its life - a massive impact in itself - and the ongoing damage to perceptions of parenthood which is no longer seen as involving unconditional acceptance, the grief, guilt and even despair caused for many aborting women is an extremely serious concern. Also highly concerning is the healthcare professions being alienated from their traditional role of promoting health and palliating suffering to assume the task of social exclusion and quality control of human lives. The aim at this point should be to get - by good means only - at least a little closer 
towards a society that respects the rights of all, and supports all parents unequivocally in cherishing each and every child.

\section{Bibliography}

Our Heartbreaking Choices: Forty-Six Women Share Their Stories of Interrupting a Much-Wanted Pregnancy, ed. C. Brooks, Bloomington 2008.

Cope H., Garrett M. E., Gregory S., Ashley-Koch A., Pregnancy continuation and organizational religious activity following prenatal diagnosis of a lethal fetal defect are associated with improved psychological outcome, "Prenatal Diagnosis" 35 (2015), p. 761-768. Finnis J., Helping enact unjust laws without complicity in injustice, "American Journal of Jurisprudence" 49 (2004), p. 11-42, reprinted with additional notes as Just votes for unjust laws, in: J. Finnis, Philosophy of Law. Collected Essays: Volume IV, New York 2011. Finnis J., Restricting legalised abortion is not intrinsically unjust, and " $A$ vote decisive for... a more restrictive law", in: Cooperation, Complicity and Conscience: Problems in healthcare, science, law and public policy, ed. H. Watt, London 2005, p. 209-245; 269-295.

Harte C., Changing Unjust Laws Justly, Washington 2005.

Harte C., Problems of principle in voting for unjust legislation, and The opening up of a discussion: a response to John Finnis, in: Cooperation, Complicity and Conscience: Problems in healthcare, science, law and public policy, ed. H. Watt, London 2005, p. 179208; 246-268.

Kersting A., Kroker K., Steinhard J. et al., Complicated Grief after Traumatic Loss, "Eur Arch Psychiatry Clin Neurosc” 257 (2007), p. 437-443.

McGovern K., Continuing the pregnancy when the unborn child has a life-limiting condition, "Chisholm Health Ethics Bulletin" 17 (2012), p. 1-12.

Redlinger-Grosse K., Bernhardt B. A., Berg K., Muenke M., Biesecker B. B., The decision to continue: The experiences and needs of parents who receive a prenatal diagnosis of holoprosencephaly, “Am. J. Med. Genet” 112 (2002), p. 369-378.

Riordan M., Maternal serum testing: Is invasive testing a passing era?, "Bioethics Research Notes" 24 (2012), p. 7-11.

Watt H., Abortion for Life-Limiting Foetal Anomaly: Beneficial When and for Whom, "Clinical Ethics” 12 (2017), p. 1-10. 
Watt H., Addressing Unjust Laws Without Complicity: Selective Bans versus Regulation, in: Contemporary Controversies in Catholic Bioethics, ed. J. Eberl, Dordrecht 2017, p. 567-582.

Watt H., McCarthy A., Targeting the fetal body and/or mother-child connection: vital conflicts and abortion, "Linacre Quarterly" 87 (2020), p. 147-160.

\begin{abstract}
Some laws cannot yet be entirely abrogated in a current political situation, though permitting grave injustices against some individuals; for example, unborn and/or disabled individuals. In supporting the passing of new 'imperfect' laws that protect only some of those who now lack protection, do we ourselves discriminate unjustly against those remaining unprotected? Or does that depend on factors such as our intentions - including what we intend that others intend? How may we collaborate with colleagues who intend, and perhaps explicitly defend, the continuation of remaining, closely-related injustices, although they are willing to join us in trying to improve some aspects of the status quo? This paper explores the moral constraints on our attempts to extend the law's protection to some, but not to all, of those individuals currently deprived of such protection and at risk of serious harm.
\end{abstract}

\title{
Keywords
}

imperfect laws, unjust laws, complicity, harm reduction, abortion 